\title{
Tides, coasts and people: culture, ecology and sustainability.
}

\author{
Owain Jones, Countryside and Community Research Institute, University of the West of England, \\ owain.jones@uwe.ac.uk \\ Natasha Barker,WWF-UK, natasha.barker@btopenworld.com
}

\begin{abstract}
Tides are an important (and often neglected) process in the UK coastal environment and globally. The Nature Conservancy Council (1991) identified 155 tidal estuarine areas around UK shores and calculated that, ' $9,320 \mathrm{~km}$ of estuarine shoreline makes up $48 \%$ of the longest estimate of the entire coast'.

These estuaries are highly dynamic natural systems and can contain vast intertidal areas. They are often linked to large conurbations through ports, industry and transport links. '18,186,000 people live in large towns and cities adjacent to estuaries' in the UK (ibid). In such ' macrotidal areas' (where tidal range exceeds 4-6 metres in height) coasts are 'considered to be tide-dominated, in that most erosional, transport and depositional processes are tidal driven' (Haslett 2008: 79). Tides not only shape the coast itself but also ecology, culture, economy, and rural/urban land use (Jones 2010a) in coastal hinterlands. Tidal dynamism brings great challenges to the governance of spaces like estuaries in physical, political and management terms (Severn Estuary Partnership 2001). They also have significant impacts on local senses of place and landscape, and other strong cultural resonances (Jones 2010b). Tidal processes and spaces are facing great uncertainty from a range of pressures/risks which include sea level rise, tidal power generation schemes (Severn Barrage), land reclamation for development (Nature Conservation Council 1991), permanent inundation for urban development (as in Cardiff Bay), and the engineering and managing of tidal rivers. In this paper Dr Jones will discuss the cultural impacts of tides at individual and local (community) level using examples from the Severn Estuary, and introduce the idea of tidal rhythms in landscape and material culture. Drawing upon the findings of a Winston Churchill Memorial Trust Travelling Fellowship, Natasha Barker (Barker 2008) will outline cultural differences between three estuaries with some of the highest tidal ranges in the world, including the Severn Estuary. The way people live and work with (or against) the tide will be illustrated, together with the way tidal landscapes are governed and observations made on the implications for sustainable management.
\end{abstract}

Keywords: tides, culture, costal management, sense of place, sustainability

\section{Introduction}

Tides are an exciting and dramatic feature of many parts of the UK coast, and other coastal areas globally. They are profoundly important in shaping the physical, economic, social and cultural geographies of the coast, and are so in ways which connect all these together. Thus they are important for those with responsibilities for managing the coasts, littoral areas, and sea margins (with an eye to sustainable management). And for those seeking to deepen our 'socio-ecological' understandings of the coasts more generally - understandings which acknowledge the complexity of any environmental issue and how they are always constructed from interacting natural and social processes. Intertidal areas - from marshy areas, beaches, to estuarine mud flats - are subject to a wide range of pressures and loss.

This is an Open Access article distributed under the terms of the Creative Commons Attribution-Noncommercial License 3.0, which permits unrestricted use, distribution, and reproduction in any noncommercial medium, provided the original work is properly cited. 
Estuaries are particularly important in the UK context, are generally highly tidal, have very powerful and important physical, economic and cultural forces at work within them, yet are often seen as empty, ugly, and thus ripe for development of one kind or another, or they suffer neglect.

This paper draws upon Dr. Owain Jones's cultural geographical work on what he terms 'tidal culture', and Natasha Barker's work on the culture and management of estuaries in UK, Russia and Canada which have some of the highest tides in the world. The Severn Estuary is used as an example as it familiar to both, and is reputed to have the second highest tides in the world and the highest in Europe. The overall aim is to draw attention to the importance and the richness of tidal culture in terms of tidal processes and intertidal spaces.

\section{Tides (a brief introduction)}

The sun and moon exert "tractive" force on the oceans, drawing the waters towards their ever moving "sublunar" and "subsolar" points. As a result of this, in combination with other forces, there is a basic tidal rhythm - a continuing cycle of low water; the flood (tide rising); high water; the ebb (tide falling); and low water again, the timings of which are constantly varying and migrating round the oceans and their coasts. Tides occur in all the oceans (to some degree) but vary markedly, and become very apparent and significant when more affected water meets land. Variously, around the world's coasts, the all important sea level continually rises and falls to make either microtidal coasts (under 2 metre range); mesotidal coasts (2 - 4 metres); or macrotidal coasts (4 metres and higher) (Haslett 2008). Tides can be diurnal (rising and falling roughly once every 24 hours, e.g. Gulf of Mexico), semi-diurnal (rising and falling roughly twice in 24 hours, e.g. Atlantic coasts of Europe and North America), or 'mixed' where the rhythm is more syncopated, as in one low tide followed by two higher tides (e.g. west coast of Canada and the United States).

The turn of the tide marks when the cycle switches from fall to rise, and rise to fall, and at the turn of the tide there is sometimes a brief period of slack or dead water. There is a monthly rhythm of increasing and decreasing tidal range driven chiefly by the moon's pull which is either exacerbated by the sun's pull (at full/new moon) to make high, spring, tides, or suppressed by it (quarter/gibbous moon) to make low, neap, tides. There is also a seasonal (yearly) rhythm within these monthly rhythms. The very highest tides - perigee spring tides occur at the equinoxes and are caused by the relative closeness of moon to earth.

Importantly, spring tides not only mark when the water level rises highest, but also when it recedes to its lowest at the other end of the cycle (because the same force that drew the water up for high tide has now moved on and is doing so at another point on the planet thus pulling water away). In other words, spring tides consist of the largest range between high and low water, whereas neap tides have a much smaller range of between less extreme high and low water levels, and varying intertidal areas are consequently exposed/inundated.

Although generally predictable due to the good understanding of the gravitational relationship between sun, earth and moon, tides in detail are dauntingly complex. The base daily, monthly and seasonal tidal rhythms are affected by all manner of interdependent variations. Bathymetry, seabed topography, coastal location, form and orientation all affect local tidal ranges. All the differing oceans of the globe have differing tidal characteristics (Carson, 1961) and all creatures of the seas in some way are touched with the tidal pull (Watson,1973). Bays and funnel shaped estuaries have some of the highest tides in the world because the surge of rising water is confined into an increasingly narrow channel. Many low lying coastal areas have vast areas of intertidal land (and areas of land which are below high water level and which are protected by sea defences). Other coastal areas can display very different forms of tidal rise and fall. For example, where high cliffs emerge from deepish water there might not 
be any intertidal land at all, but only a ceaseless rise and fall of tidal level against the cliff face. Tides do not only create water level rise and fall but also tidal currents that sweep along coasts in complex temporal and spatial rhythms and patterns.

To complicate things further, tidal rhythms are affected by weather. Low atmospheric pressure might exaggerate the tidal rise, and high pressure suppresses it. Wind speed and direction can also either exaggerate or dampen tidal range and change precise times of high and low water. A lee tide is when the tide flow and wind direction are in concert, and a weather tide is when the wind blows against the tide. Storm tides, sometimes responsible for devastating floods (as in Eastern England in 1953), occur when high winds and low pressure combine with a high tide in such a way as to pile water into low lying coastal areas and estuaries.

In thinking about tidal rhythms it is important to note that times of high and low water do not synchronise with the 24 hour day cycle in any simple way. 'Because the earth rotates in relationship to the moon once every 24.8 hours, high tides occur on average every 12.4 hours' (Young 1988: 27). Thus the timings of high and low water slowly migrate across the 24 hour grid. The other monthly cycle of peaks (spring tides) and lows (neap tides) is 14.8 days. See McCully (2007) for detailed description of tidal processes, and Koppell (2007) on tidal interlationships with ecology and society.

\section{UK, and Severn Estuary as an example}

The United Kingdom is an island nation with an estimated coast line of $17,820 \mathrm{~km}$. All the intricacy and variety of that coast is washed by some of the highest tides in the world. Estuaries (which by definition are tidal) form a large part of the UK coastal geography and they can contain vast intertidal areas of lands (e.g. Morecambe Bay, 61506.22 ha., The Wash, 107761.28 ha.). The Nature Conservancy Council (1991) identified 155 estuaries around the British coast. They calculated that, 'the 9,320 km. of estuarine shoreline makes up $48 \%$ of the longest estimate of the entire coast', and that ' $18,186,000$ people live in large towns and cities adjacent to estuaries'. These landscapes, which can bring nature/wilderness into the heart of urban conurbations, or form our most remote, wild, wildlife rich landscapes, are distinguished by unique temporal and spatial characteristics which we explore below.

\subsection{Severn Estuary}

The Severn Estuary is $557 \mathrm{~km} 2$ with around 18 percent of this being intertidal (100 km2). At Avonmouth Docks (Bristol), at the spring (equinoxal) tides the difference between high and low water is some 14 metres! This is the highest tide in Europe and often cited as the second highest tidal range in the world. An impression of the difference in high and low water can be gained by looking at dock infrastructure such as locks at low water (figure 1). The force of this natural process shapes the very estuary itself and also the life in and around it. A huge wedge of rising water presses up the estuary and into the flank of Wales/England, filling it up to the very brim of its sea defences and washing back up the normally draining rivers, though both urban and rural landscapes. The Severn bore - a large tidal wave which washes up the lower reaches of the River Severn on days of the higher tides is a famous natural phenomenon and considerable tourist attraction. 


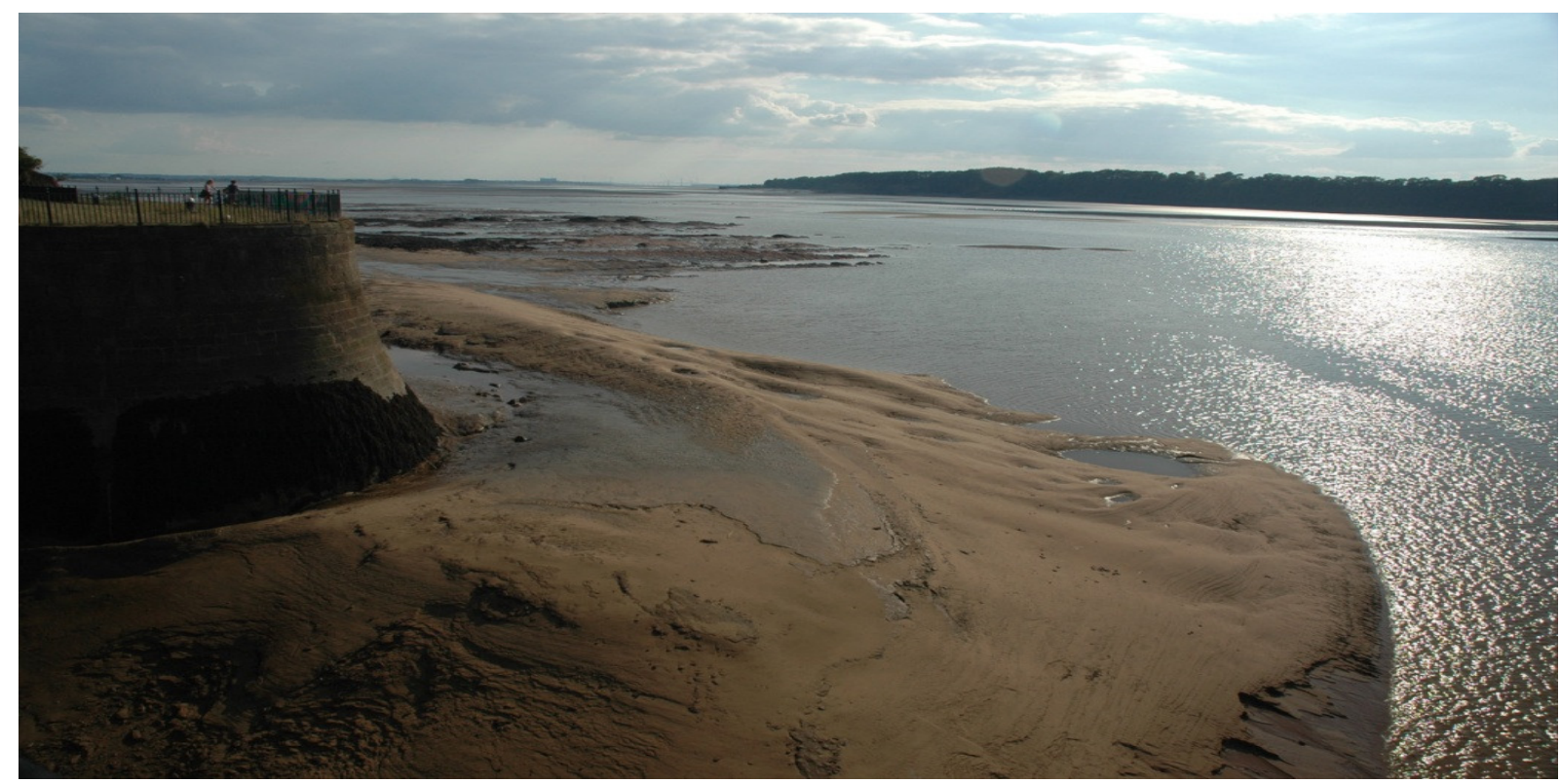

Figure 1. Low tide, Sharpness docks, Severn Estuary. High tide will take the water level to the very top of the wall. (Note the figures for scale)

This highly dynamic, powerful process presents huge challenges to processes of local government and environmental management. As the Severn Estuary Partnership (SEP) put it;

Britain's longest river brings vast quantities of water into the Severn Estuary. Europe's biggest tide takes masses of water back up into the mainland. The mighty Severn influences the ways we live in many ways - and deserves all the attention we can give it! (SEP, 2005, p .2).

The estuary forms the sea division between South West England and South East Wales and the coastal edge of 11 local authority areas (unitary boundaries) - Devon; Somerset; North Somerset; Bristol; South Gloucestershire; Gloucestershire; Forest of Dean; Monmouthshire; Newport; Cardiff and the Vale of Glamorgan. Approximately $80 \%$ of the estuary's $370 \mathrm{~km}$ shoreline is lined with sea walls (regular, grassed earth banks in rural locations; concrete walls in ports and towns). These stop the very highest tides flooding low lying surrounding land, thus marking the upper limit of the intertidal areas and forming their "immediate landward margins". These sea walls are, in many places, open access and used for recreational purposes, and accessing/viewing the intertidal areas.

\section{Special Character and Importance}

The tides and intertidal areas are a fundamental and unifying feature of this area's landscape character. They are extraordinary visual spectacles in themselves and the intertidal areas and margins are home to a rich combination of internationally important natural and culture heritage. Some 3,000,000 people live around the estuary in large urban conurbations (Cardiff, Newport, Gloucester, Bristol); smaller towns (Weston, Cleveland, Chepstow), and remote rural settlements, set in open, rich, agricultural land. It is worth noting that the other coastal areas in the world with comparable tidal ranges are in more remote rural landscapes (e.g. in Canada and Russia), so the Severn Estuary is the most tidally dynamic estuary in the world which is also close to large population centres.

The estuary's intertidal areas vary greatly in a number of respects. From inaccessible $\mathrm{mud} / \mathrm{sand}$ banks and channels only exposed at the very lowest tides, to accessible areas of 
beach, rocky foreshore, and salt marsh meadows which are only flooded the very highest tides. All these areas are interconnected as a living landscape through a range of means which include the visual, physical processes, and very high ecological and other heritage values (see below). Although some areas of the landscape are remote and hard/impossible to access, it must be stressed that this is a uniquely public landscape (in part because of it visual openness) and because of the open access to the coast/foreshore in many places.

The times of high and low water can bring a very different pattern of temporal life and sense of time to the landscape in natural, cultural and economic terms. There are unique, and always varying patterns and rhythms of space/time and related practices of landscape, such as intertidal commercial fishing, livestock farming on salt marshes, work related to ports and coastal trading, and a range of recreational activities (walking, fishing and bird watching). The tidal processes speak to the aliveness of the landscape and the never-ending gravitational pas de trois of earth, sun and moon, and create huge, ever inter-changing vistas of shore, intertidal area, sea, sky, space and light. These are enjoyed by many people, including those who work in relation to the estuary, live or work overlooking the estuary, visit it/use it recreationally, and those who see it in their travels along its shores and over its bridges. The estuary is vital to the local and regional economy being the site of tourist resorts (tourist beaches such as Weston, Barry and Bream are part of the intertidal area), large ports, nuclear (and other power stations) and spectacular toll bridges. The landscape is on such a scale, and is so visually dynamic, that these large industrial developments are absorbed into it and it retains a sense of wildness and remoteness, even when in close proximity to the densely populated urban areas. The drama of the tidal areas is the focus of a number of artists writers/poets (e.g. "Water Table" by Philip Gross, winner of the 2010 T. S. Elliot poetry prize, and Alice Oswald's "Sleepwalk on the Severn").

\section{Cultural Heritage \& Crafts}

The tides have shaped the patterns and rhythms of social and economic life around the estuary for millennia and this has created a rich built/cultural/craft heritage of local, national and international importance in the intertidal areas and their margins.

Maritime Heritage. The estuary has a very important maritime heritage both of international and local trade through the ports, harbours and craft associated with them. Two very famous and distinctive types of craft evolved to work the tidal waters of the estuary. The Severn pilot cutter was built to cope with the fast, turbulent tidal waters of the estuary, and the Severn trow for coastal trading out of small inter-tidal creeks and harbours. The tidal waterways of the estuary have made some of the largest and most important ports in UK (e.g. Cardiff, Bristol) which are bound up with stories of international trade and empire. Many small tidal harbours also existed. Some remain (e.g. Lydney), though many are now 'lost harbours'. Other built heritage remains are evident around the margins of the estuary's intertidal areas. For example, coastal navigation features, (e.g. huge abandoned fog horns); the hulks of many traditional Severn craft which can be found at the famous 'boat graveyard' at Purton, Gloucestershire, which has been described as one of the most important marine archaeology sites in the UK; and the slipways and jetties of tidal ferries (see below).

Other Transport and Military Heritage. There is an equally rich local/regional heritage of terrestrial transport networks in the forms of ferries, railway tunnels, bridges and swing/transporter bridges which have resulted from the need to travel across and around the estuary as efficiently as possible. For centuries a series of ferries were the only means of crossing the estuary and these have left a built heritage around the margins of the intertidal areas (e.g. wooden jetties, old stone slipways, many now abandoned). These ferries 
crossings (which had their own small fleets of boats and associated boarding houses) and the timings they operated to, were shaped by the tidal rhythms. They were gradually replaced by firstly the Severn Railway Tunnel (1886) and then the two vast Severn road bridges which were opened in 1966 and 1996. These developments have transformed the way local populations move around and across the estuary. In many senses they have removed the intimate contact the ferries would have given passengers to the tidal landscapes, but the views from the Severn Bridges have at least opened up other vistas. Given the strategic importance of the estuary there is also a military heritage around its margins, particularly from the 19 century and Second World War. (Some of this is very much at risk due to a lack of upkeep).

Traditional fishing and agriculture. A range of traditional harvesting practices have grown up in association with the inter-tidal areas and their margins. The most significant of these are a set unique fishing techniques which include:- Lathe net fishing (which is done by wading in the incoming tidal stream); long net fishing from small boats; intertidal fish weirs (where willow traps are placed at low tide and checked at the next low tide) (all aimed primarily at catching salmon migrating up the estuary to breed and spawn in the rivers); 'mudhorses' (a sort of sleigh used to move across the more treacherous and remote mud banks in order to gather shellfish), and a strong and lucrative tradition of netting for elvers (immature eels). Line fishing from intertidal margins remains an important recreational activity and is done in conjunction with tide times. The tragedy of the drowning of 21 Chinese migrant workers while cockle picking in Morecambe Bay in 2004 show the danger of tidal landscapes.

Agricultural Heritage. Marshy intertidal areas around the estuary were first settled thousands of years ago, as demonstrated by archaeological finds of walkways across the Somerset Levels. The rich land around the estuary was gradually reclaimed for farming and settlement. The way of life of livestock grazing (mainly sheep \& cattle) on the estuary's hinterland has produced distinctive local products (e.g. salt marsh lamb). The lowland wet grazing marsh and adjacent salt-marshes are now also managed for nature conservation purposes alongside agricultural usage.

Archaeological heritage. Given the above traditions it is not surprising that the estuary is an internationally important area for archaeology. The intertidal areas contain significant relics of ancient subsistence agriculture and settlement. Consequently an archaeological research group, "The Severn Estuary Levels Research Committee" has been established at Reading University to focus on this heritage. The dynamic, and in some ways fragile, environment of mud flats and sand banks, shifting river channels and soft shore line makes it particularly vulnerable to both human and naturally induced change (see below).

Recreational heritage. The intertidal areas and their margins host a wide range of tide related recreational activities such as walking, bird watching, fishing, beach sailing, tourist beaches - and more modern activities such as jet skiing and surfing the Severn Bore. The beaches and piers of Weston-Super-Mare, Clevedon and Barry are classic British seaside holiday spaces and very much part of the estuary's heritage and landscape (some 'lost' recreational heritage sites such as abandoned lidos and derelict piers). In some places the intertidal/foreshore areas are easily accessed (both through formal and informal provision) and used on a daily basis for a range of activities. But in many other areas there are a limited number of slipways and moorings compared to many other UK estuaries. Public access to safe areas of the intertidal zone, and supporting interpretation of it, is lacking. Consequently, overall, there is limited interpretation and therefore public awareness of the value of the estuary and its unique, internationally valuable tidal landscape. 
Natural Heritage. Natural England has identified the Severn Estuary as one of the 24 UK Maritime Natural Areas because of the tides and the effects these have on natural heritage and on geological and geomorphological features. The Wildlife Trusts (2010) say that 'the vast tidal range of the Severn Estuary makes it one of the great natural wonders of the world', and that 'the estuary's fast flowing, silty water has, over thousands of years, created an ecosystem unlike any other in the UK'. The estuary's intertidal areas provide some of the most important habitat for wading birds in Europe. They support some 200,000 migratory wading birds each year and are consequently protected under a whole range of high level national and international conservation designations. They are a key focus for a number of significant conservation and education bodies such as the RSPB, the Wildfowl and Wetland Trust, and The County Wildlife Trusts. The ecology of the estuary can be considered in aquatic, intertidal and littoral/terrestrial areas. The waters of the estuary have a complex aquatic biodiversity which is shaped by the brackish nature of the estuary waters (i.e. a mixture of fresh water from the rivers and salt water from the sea). It is constantly being mixed in differing patterns by the tides. The fast flow of the tides also means a vast amount of silt is suspended in and moved about by the estuary's waters.

The mosaic of intertidal areas has a biodiversity to rival any ecosystem, including tropical rainforest and mangrove swamps, this including the bird life that feeds on the rich mudflat ecology. The landward margins of saltmarsh and lowland grazing marsh have unique, littoral and terrestrial ecologies of plant and animal life which vary according to the frequency of tidal inundation. All three of these habitats: estuary water, inter-tidal areas and littoral margins are interdependent. Pressure or impacts on one habitat (such as pollution in water or development over salt marsh) can affect the ecology of other habitats.

The combination of all the above means that the estuary and its intertidal areas has a very strong sense of place which is keenly felt by many of those who live around its shores, particularly for smaller communities, and those whose work and/or recreational practices are still linked to the tidal landscape. It should also be noted that while the tidal estuary forms a very distinct landscape in itself, it is also inextricably linked to the entire Severn River Britain's longest and 'wildest' river - and other important rivers such as the Wye, Avon, Usk, and Taff which drain also into the estuary and are tidal in their lower reaches. Thus the 'health' of this estuarine landscape underpins that of some of the UK's most important rivers.

Threats to the estuary's inter-tidal areas and heritage. Many of the traditional practices and the crafts associated with them, such as boat building and repairing, ferrying and navigation, and those associated with the local forms of fishing/agriculture have declined to vestiges kept up by a few practitioners and enthusiasts. Barker (2008) suggests that many of 3 million people who live around the estuary (especially those in large conurbations) have 'lost touch' with the tidal/estuarine landscape. This leaves those who do access the estuary shoreline and intertidal areas as a passionate minority. Intertidal areas are often taken-for-granted by the public and even planning authorities in the UK and beyond. They can be regarded as 'empty' and even ugly, and thus are at risk of neglect, abuse and/or development, even if they are under nature conservation designation. For example the Taff Estuary intertidal areas in Cardiff (which adjoined the Severn Estuary) have been permanently flooded to create Cardiff Bay for the purposes of "urban regeneration", even though they formed a Site of Special Scientific Interest, and a very distinctive, locally vibrant wild landscape in the heart of this large city. Because of such pressures and attitudes, and other reasons, the tidal Severn estuary and river faces an unprecedented level of threat and uncertainty in regard to both its 
natural and cultural heritage, on a range of spatial and temporal scales. This also applies to at least some other estuaries and intertidal areas

Professor Simon Haslett, a leading expert in the estuary's archaeology, has recently written that the heritage resource is under a significant threat of loss. A complex set of sometimes conflicting demands is placed upon the tidal estuary, for example between recreational uses, resource extraction, nature conservation, waste discharge, agriculture (grazing of salt marshes), transport needs, shoreline management/development and public access. Risks to the landscape include; coastal development (for housing, transport, industry and power generation); pressure on natural systems (e.g. pollution /water quality), aquatic biodiversity decline (e.g. salmon and eels); resource extraction (e.g. dredging of building aggregates) and perhaps most significantly, major tidal power generation schemes and the potential impact of climate change through sea level rise.

\section{Tides, sense and rhythms of place}

We are interested in how tidal rhythms are folded into local processes, materialities and practices of places/landscapes and how tidal rhythms might distinctively pattern everyday life. Matless (2009) discusses the wave patterns sculpted into the sands of estuarine intertidal landscapes as studied by Cornish in the 1920s. It could be argued that tides sculpt other material and lived patterns of life in coastal areas. They will create differently different rhythmic traces in social and cultural geographies of work, recreation, community and individual identity. This becomes part of landscape 'sense of place' and in turn becomes a factor in how these places are and can be managed.

This local temporal patterning of life can contribute to what Common Ground (Clifford and King, 1993) call local distinctiveness. It can contribute to what Thrift (1999) calls 'ecologies of place'. In these accounts however it is the distinctive materialities, cultures and identities which are focused upon. There is less attention to the distinctiveness of temporal patterning. Massey and Thrift (2003) and Massey (2005) have developed Thrift's notion of ecology of place into more fully processual view, which sees places and landscapes as outcomes of intersecting flows (material and non-material, human and non-human) coming together and coalescing into knowable forms. The temporal nature of these comings and goings and the rhythmic patterning they can bring, merits much further consideration. Tidal processes bring very distinctive temporal processes to coastal and estuarine landscapes such as the Severn Estuary.

This idea of intersecting rhythms of all manner of things, including economic process, day and night, weather, tides, animal life cycles is beautifully illustrated by Young (1988), at the very end of his book on the interlinkages between 'natural rhythms and human timetables'. Seeking a vivid example for his coda, he turns to a tidal landscape, in fact the Bristol Channel, which forms the western seaway leading into the Seven Estuary.

It is dawn at an English West Country fishing port on a summer morning. Norman Widdicombe, the skipper of the Mary Jane, has been woken by an alarm clock which is reset each night to a different time (262).

Young then goes on to describe the complex calculations this commercial fisherman has to make to plan his trip. He will be after mullet and squid 'who like swimming against a strong tide'. He is also aware of the fishes' seasonal migrations. But he needs to be aware of other timings and rhythms as well. It is Wednesday and he needs to get out to sea and back to make the Friday fish market. There is no market on Saturday. Also, the cycle of fish prices are currently in his favour - but may not be for long. The weather will have a bearing on the timings too, how long and difficult the sail to and from the fishing grounds will be. He has to 
decide whether to wake his two man crew by telephone (families whose temporal rhythms are also linked to tides, seasons, weather and economy). Thus Young paints a picture of many rhythms and temporal patterns - the seasonal habits of the fish, the tides, the weather, day and night, the fish trade prices, and the weekly rhythm of the commercial fish markets in complex, geared interplay, like some lush orchestration with different parts playing at different tempos and beats. Landscapes become timescapes (Adam, 1998) in which intersecting rhythms are key features.

In his notion of rhythmanalysis Lefebvre (2004) makes the case that spaces (such as cities) have multiple types of temporal patterns and rhythms (e.g. linear and sequential, cyclical), and this is key to understanding the pulse(s) of life within them. Lefebvre actually highlights tides as one profound form of cyclical, natural rhythm, which, he feels, can shape the very nature of cities. He makes the fascinating point that cities on the Mediterranean coast (where tidal rise and fall is generally far less) might have fundamentally differing temporal/rhythmic signatures to cities on the Atlantic coast where tidal ranges are much greater.

We shall [ ] begin by indicating briefly certain contrasts between Mediterranean and oceanic towns. These are governed by the cosmic rhythms of tides - lunar rhythms! With regards to Mediterranean towns, they lie alongside a sea with (almost) no tides; so the cyclical time of the sun takes on a predominant importance there. Lunar towns of the oceans? Solar towns of the Mediterranean? Why not? (Lefebvre, 2004: 91)

\subsection{Tides in literature and art}

Sculptors, artists and photographers have explored intertidal spaces and their margins in their work. Of course, representing the processes and rhythms of tides are challenging in the visual arts but examples abound. Turner painted estuary scapes. Coster and MacDonald (1989) produced a wonderful photographic essay, Man Made Wilderness, about people using the 'beaches' of the Tees Estuary at various states of the tide alongside the heavy industrial sprawl of the area. The Cornish artist Wilhelmina Barns-Graham produced a series of delicate etchings reflecting the changing wave patterns of the sea - Water Rhythm; Linear Movement (Incoming Tide Series).

Here we more interested here with artists who work with tides in a more performative, material sense. Paul Nash's work Wooden Boulder can be called an ecological/elemental art work in that it incorporates natural (tidal and other) processes. A wooden (solid oak) boulder, three feet in diameter was created in the late 1970s. Partly by accident (see Deakin, Wildwood, (undated volume) for full account) the boulder got stuck in a mountain stream in Wales. From then on, at times when the stream was in spate, the boulder was occasionally moved down-stream by the force of the water. The artist began to chart this progress. Eventually the boulder reached the tidal reaches of the River Dwyryd (Wales). There according to Deakin (Wildwood: 163) the bolder began to,

wander the water of the estuary, mysteriously disappearing up creeks, endlessly doubling back on itself in the ebb and flow, moving with each new tide, responding to the moon. By now utterly obsessed, Nash went searching for it in a boat and lost it all together for a while. He even put out wanted posters around the estuary. During those chilly winter days of hide-and-seek he studied the tides and pored over charts, mapping the uncertain voyage. Then one January day the great oak apple reappeared on a saltmarsh and seemed almost settled for a moment until that equinox tide of 19 March 2003 floated it free. Nash watched from the boat, as the heavy sphere floated, most of its body submerged 'like a seal'. It was just a far off dot when he last saw it on 30th of 
March. Somebody sighted Wooden Boulder floating close to the estuary's mouth a few days later, but it vanished in April 2003. (163)

More recently two high profile UK artists, Richard Long and Simon Starling (both Turner Prize winners), were commissioned to produce artworks for Spike Island Gallery (Bristol) which is located between the Bristol floating harbour and the tidal Avon. Both choose to work with the tides that wash past the gallery, through the city, and up and down the Avon, linking to the wider Severn Estuary. Long (as he has previously) produced artwork using mud from the intertidal zone of the river. He also reproduced a 1990s art work which 'goes' thus:

\section{A RIVERSIDE WALK UP THE AVON \\ FOLLOWING A RISING TIDE \\ FROM THE MOUTH AT LOW TIDE \\ TO THE TIDE HEAD AT HIGH TIDE}

In other words, the walk, following the front of a rising tide (which on rivers can often be precisely identified by a sharp change in water pattern, and a line of flotsam (floating debris)), and that statement of the work as a print, is the art work itself.

Starling produced a contemporary relational performance piece. This artwork consisted of a large piece of rock on a plinth which doubled as a raft being floated up the Avon on a high tide which was then lifted from the river and placed in the gallery. This echoed the way the tide has been used for trade and transport and how it connected Bristol to the sea trade routes of the world and to local coastal trading networks. It should not be forgotten that the slave ships which made Bristol a centre of the UK slave trade floated up the Avon on high tides.

Perhaps the most significant 'tidal sculpture' in the UK is Anthony Gormley's Another Place. The piece consists of a 100 life-size identical cast iron figures spaced along a two mile section of Crosby Beach in North West England. The figures all are orientated the same way, apparently looking out towards the sea horizon. They are placed at differing heights on the beach and at high tide are nearly all submerged. At low tide they are all exposed. In between some figures will be partially submerged, others at the water's edge and yet others standing clear of the water. The ceaseless, varying cycle of the tide becomes a critical competent of the work. Many photographs of this artwork can be found on the web but these of course only show it at a given moment. In a sense this work cannot be fully seen, as each tide, happening through day and night, and varying in heights from neap to spring, will bring a different extent and speed of inundation of the figures. The figures will also change colour each time they dry after submersion (cyclical rhythm), and they will also change over time (linear rhythm) as the sea, and possibly sea creatures such as barnacles, affect the fabric of the figures.

\subsection{Loss of tidal landscapes and senses of place}

Tides themselves cannot be stopped any more than we can stop the moon revolving round the earth or drain the oceans dry. But the affects of tides, their rhythms and spatial ranges, and the tidal cultures they can generate, can be adjusted or even smoothed out by material adjustments to the landscape and through technological interventions. This then speaks to ideas of social time smoothing over, and becoming removed from, natural temporalities. 
In some instances, forms of transport have had changing social relationships to tides. In the case of the Severn Estuary until the late 19th and 20th centuries the only immediate routes from Wales to South West England were via the lowest bridging point on the Severn at Gloucester, or ferries which crossed the estuary further downstream that were developed commercially in the 17th and 18th centuries. One of these ferries became part of Brunel's Great Western Railway network, with a line to the shore and ferry head, and hotel constructed to accommodate passengers waiting for a tide dependent ferry, and then the line continuing on again on the far shore. From 1877 onwards the Severn Railway Tunnel (one of the great engineering feats of Victorian England) provided an alternative to the ferries (but did not kill them off) and travellers swapped the wait, the drama and views of the ferry crossing for the darkness and the clatter of the brick lined tunnel, which, of course paid no heed to tidal times. The ferries persisted well into the 20th century carrying cars and passengers until two vast Severn road bridges were opened in 1966 and 1996.

Prior to engineering of the Severn Estuary coastline the tidal landscape would have been much more extensive with highest tides flooding inland, particularly into the low lying wetlands of Somerset and Gwent, making them very different landscapes in terms of ecologies and rural economies to what they are today. The whole of the Somerset Levels would have been part of the estuary (tidal) system. Today it still remains so in a sense, but water levels and flows are controlled by drainage systems, sluices etc.

Despite this confinement of the tides, the intertidal areas of the Severn estuary remain extensive and has the range of ecological and cultural heritages outlined above in place. In other UK estuaries large areas of intertidal land have been reclaimed. For example the intertidal lands of the Tees Estuary (UK) have been reduced from approximately 3,000 hectares to 500 hectares in a series of land reclamations for agricultural and built development since the 18th century (figure 2).

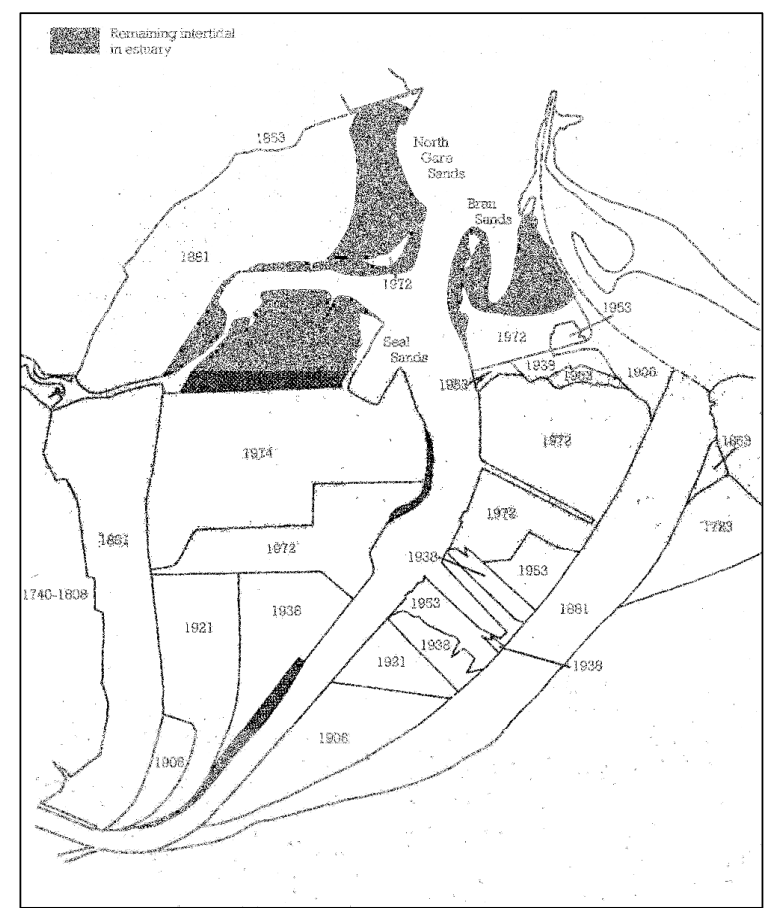

Figure 2: A map showing the reduction of intertidal land through reclamation on the Tees Estuary UK. (NCC 1991: 368) 
The rhythms and ecologies of tides can also be smoothed out by making intertidal areas permanent areas of high water. A very prominent and controversial example of this was the creation of Cardiff Bay. This entailed separating on the Taff Estuary - which opens onto the wider Severn Estuary - with a barrage which ponds the water of the Taff river into a permanent high water lake on the Western edge of the city. This was done for the sake of 'urban regeneration', as the extensive mud flats of the estuary that low tide revealed were seen as problematic to the area's image. Indeed, adverts placed by the Urban Development Corporation to promote the idea labelled the tidal estuary as 'dormant space' and the projected 'docklands' style lake and development as 'vibrant space'. However, the Taff Estuary was a Site of Special Scientific Interest because of the birdlife it was habitat to, thus the building of the barrage was opposed by a comprehensive alliance of local and national nature conservation bodies. Also the estuary had a distinctive cultural ecology of place with small industrial units and a community of boat keepers, fishermen, walkers, all of whom would have had relationships with the tidal river mouth.

\section{Tides and sustainable management}

Research comparing the tidal landscapes of three estuaries with high tidal ranges illustrated how people live with (or against) the tide at different stages of societal development has been conducted by Barker (2008). This further expands the idea of tidal culture and brings the discussion to management more directly.

\subsection{Living with tides}

In one of the most remote regions of the world, northern Kamchatka, the Penzhinskaya Guba (estuary) is populated by around 3000 people living in what is in effect a wilderness area. They experience sub-zero temperatures for around 8 months of the year. During summer months people harvest the abundant salmon stocks and forage for fruits as there is very little land for agriculture. Transport of goods is limited to old barges which land on beaches with the rise and fall of the tide and there are no port/harbour facilities. Coal is harvested from a small nearby mine for local consumption. Import of goods arrives a few times during the year by ships from Magadan and Petropavlovsk and in smaller amounts, with passengers, by a weekly helicopter. People live closely in tune with the rhythms of the tide as they depend on it for their livelihood. Penzhinskaya Guba is similar in size to the Severn Estuary and Bristol Channel with a slightly lower tidal range of around $14 \mathrm{~m}$, which is predominantly diurnal as opposed to semi-diurnal. The tidal landscape is pristine in terms of not being engineered for flood defences or land reclamation. This landscape forms a fascinating glimpse of the Severn Estuary would once have been like. The vast open landscape demonstrates how large the influence of the tide can be when un-hindered by shoreline development. The small population living a subsistence lifestyle illustrates how people living with the tide exert very little change on the tidal landscape. Their rate of resource extraction appears to be well below any environmental carrying capacity limits - people are a small part of the estuary's larger ecosystem.

\subsection{Balancing tidal culture with development}

In the Bay of Fundy in Atlantic Canada, some 300,000 people live around the shores of the Bay across Nova Scotia and New Brunswick. Traditional communities were colonised by Europeans who reclaimed marshland for agriculture and started construction of dykes. Consequently, some $80 \%$ of the shoreline has been changed by the formation of embankments and defences against unhindered tidal inundation - a similar extent to the 
Severn Estuary, However, with only some $10 \%$ of the population there are wider 'buffer' zones between high water and many of the dykes around the Bay of Fundy. This gives the appearance of a more natural landscape.

People living around the Bay of Fundy are well aware that they occupy the site known to have the highest tidal range in the world. Millions of tourists visit from all over the world each year to visit well known sites such as 'Hopewell Rocks', experience white-water rafting trips on the tidal rapids of the Shubenacadie and the elaborate interpretation and visitor centres around Fundy National Park. The Canadians have a strong sense of pride in the immense tidal range of Fundy, over $16 \mathrm{~m}$, and promote access and facilities for people to directly experience the landscape. Consequently, people around the Bay of Fundy are more likely to be able to manage a sustainable lifestyle. The wide cultural awareness and connection to the tides brings a level of respect not seen in the majority of the population living around the Severn Estuary in England and Wales. This is reflected in the way people and the Canadian Government are approaching the assessment of options for tidal power generation. Experience from causeways built across tributary rivers leading into the Bay of Fundy has shown how high siltation causes significant disruption to tidal patterns and has consequences for erosion, flooding, water quality and farming. Investment into large scale development of a tidal barrage has therefore been ruled out due to the forecasted disruption to the ecosystem and non-sustainability of the engineered structure. This example shows how a society living in a manner more connected to the tide is more aware of the implications of large scale development and can see the long term disbenefits as opposed to the shorter term gain.

\section{Conclusions Tides and Developed Society?}

Coasts and estuaries contain some of Britain's most fragile and valuable natural habitats. People put huge pressure on these sensitive environments through industry, agriculture, housing and transport infrastructure. Sustainable estuary management is advocated by the voluntary Severn Estuary Partnership, but the drive for economic development by over 3 million people living around the Severn Estuary is predominant. This level of development has changed people's lifestyles and the predominately urban lifestyle disconnected people from the tidal landscape. Whilst there is no concrete evidence to demonstrate that this lifestyle is unsustainable, the rate of resource extraction and consumption far exceeds that demonstrated by communities around Penzhinskaya Guba and the Bay of Fundy.

It follows that for people to work towards the sustainable management of resources, there either needs to be greater quantification of the environment's carrying capacity or people intuitively learn to live in tune with their environment. Finding ways for people in a highly developed society to re-connect with their tidal landscape - through art, literature, and direct experience - could help to achieve more sustainable living patterns. We leave the last words to the geographer Bill Adams who says of the beaches of East Anglia,

these places seem to have a very particular power. This lies in the sense of freedom that beaches offer, their sheer openness, and the novelty of the life they support. They are places that literally have a life of their own, where rhythms of tides and seasons set an agenda that seems to stand outside human time (1996, 2/3).

\section{Acknowledgements}

Thanks to CoastNet for inviting Dr Jones to give this paper and supporting it financially. 


\section{References}

Adam, B. (1998) Timesscapes of Modernity, London: Routledge.

Adams, B. (1996) Future Nature, London: Earthscan.

Association of Severn Estuary Relevant Authorities (ASERA) (2010) What's special about the Severn Estuary European Marine Site?

http://www.severnestuary.net/asera/severn.html) (accessed 2702 2010)

Barker, N. (2008) Managing Tidal Change, Final Project Report of Winston Churchill Memorial Trust Travelling Fellowship Award 2006. Report available from natasha.barker@btopenworld.com.

Carson, R. L. (1961) the Sea around Us, Oxford: Oxford University Press.

Cartwright, D. E. (2000) Tides: A Scientific History, Cambridge: Cambridge University Press.

Clifford, S. and King A. (eds.) (1993) Local Distinctiveness: Place, Particularity and Identity, London: Common Ground.

Deakin, R. (undated) Wildwood, London, Hamish Hamilton.

Haslett, S. (2008) Coastal Systems, Second Edition, London, Routledge.

Jones O. (2010b) 'The Breath of the Moon': The Rhythmic and Affective Time-spaces of UK Tides, in T. Edensor (ed) Geographies of Rhythm, Oxford: Ashgate, pp 189-203.

Jones O., (2010) 'The Breath of the Moon': The Rhythmic and Affective Time-spaces of UK Tides, in T. Edensor (ed) Geographies of Rhythm, Oxford: Ashgate, pp 189-203.

Jones O., and Cloke P., (2008) 'Non-human agencies: tree is place and time', in C. Knappett and L. Malafouris, (eds.) Material Agency: towards a non-anthropocentric approach, Guilford: Springer. pp 79-96.

Jones, O. (2010a) Moon beats: tracings of the polyrhythmic material cultures of tides, Environment and Planning A (forthcoming)

Koppell, T. (2007) Ebb and Flow: Tides and Life on Our Once and Future Planet, Toronto: Dundurn Group.

Lefebvre, H. (2004) Rhythmanalysis: space, time and everyday life, London: Continuum Books.

Massey, D. (2005) For Space, London: Sage.

Massey, D. and Thrift, N. (2003) The passion of place, in R. Johnston and M. Williams (eds) A Century of British Geography, Milton Keynes: OUP/British Academy.

McCully, J. G. (2007) Beyond the Moon: A Conversational, Common Sense Guide to Understanding the Tides, Hackensack: World Scientific Publishing.

Nature Conservancy Council (1991) Nature Conservation and Estuaries in Great Britain, Peterborough, NCC.

Matless, D. (2009) Nature Voices, Journal of Historical Geography, 35, 1, 178-188.

Severn Estuary Partnership (2001) Strategy for the Severn Estuary, Cardiff: SEP.

Severn Estuary Partnership (2005) Severn Tidings, Issue 7, Autumn, Cardiff: SEP.

Thrift, N. (1999) Steps to an ecology of place', in D. Massey, P. Sarre, and J. Allen (eds), Human Geography Today, Oxford: Polity, 295-352.

Watson, L. (1973) Supernature: The Natural History of the Supernatural, London: Book Club Associates.

Wood C. H. (2008) Time, Cycles and Tempos in Social-ecological Research and Environmental Policy, Time and Society, 17, 261-282.

Young, M. (1988) The Metronomic Society: Natural Rhythms and Human Timetables, London: Thames of Hudson. 